\title{
Evaluation of Bread Wheat Varieties to Dominant Races of Stem Rust (Puccinia graminis f. sp. tritici) Pathogen
}

\author{
Alemayehu Hailu Welderufael ${ }^{1}$, Getaneh Woldeab Wolderufael ${ }^{1}$, Woubit Dawit Bedane ${ }^{2}$, \\ Endale Hailu Abera ${ }^{1}$
}

${ }^{1}$ Ethiopian Institute of Agricultural Research, Plant Protection Research Center, Ambo, Ethiopia

${ }^{2}$ Plant Science Department, Ambo University, Ambo, Ethiopia

\section{Email address:}

alemayehuhailu65@yahoo.com (A. H. Welderufael), getanehwoldeab@gmail.com (G. W. Wolderufael), woubit123@yahoo.com (W. D. Bedane), endalehailu@gmail.com (E. H. Abera)

\section{To cite this article:}

Alemayehu Hailu Welderufael, Getaneh Woldeab Wolderufael, Woubit Dawit Bedane, Endale Hailu Abera. Evaluation of Bread Wheat Varieties to Dominant Races of Stem Rust (Puccinia Graminis f. sp. Tritici) Pathogen. Science Innovation. Vol. 3, No. 6, 2015 , pp. $121-126$. doi: $10.11648 /$ j.si.20150306.20

\begin{abstract}
Stem rust (Black rust) caused by Puccinia graminis f. sp. tritici is one of the most important air borne diseases of wheat (Triticum aestivum) in the central high lands of Ethiopia, including west and southwest Shewa zones. The pathogen is capable to produce new physiological races that attack resistant varieties and develop epidemic under optimal environmental conditions which results in a serious yield loss. However, information on the reaction of bread wheat varieties to dominant races in west and southwest Shewa zones is lacking. Therefore, the present study was conducted to evaluate the reaction of 12 commonly grown bread wheat varieties by artificial inoculation against the major virulent races at seedling stage in green house (TKTTF and TTKSK) and at adult plant growth stage under field condition (TTKSK). In the green house test, varieties Huluka and Ogena showed resistance to TTKSK and TKTTF races. Likewise, the two varieties showed moderately resistance reaction at adult plant growth stage with terminal severity of below $10 \%$. Whereas, ET-13A2 was susceptible to both races at both plant growth stages. Digalu was susceptible to TKTTF, but resistant to TTKSK at seedling stage, and under field condition it showed severity of 63.3S. The lowest mean AUDPC was recorded on the Ogena, Huluka and Shorima varieties with 37, 52.7 and 103.7 values in the mentioned order. In contrast, the highest mean AUDPC of 1225 on Morocco and 805.8 on Digalu were recorded. Similarly, the maximum mean disease infection rate was also recorded on Morocco and Digalu varieties. Hence, varieties Ogena and Huluka that showed resistance to both virulent races at seedling and adult plant growth stages can be used as sources of resistance in wheat breeding program.
\end{abstract}

Keywords: Wheat Stem Rust, Race, Puccinia Graminis $f$. sp. tritici, AUDPC, Infection rate, Severity

\section{Introduction}

Wheat (Triticum aestivum) is one of the major crops cultivated in Ethiopia. Ethiopia is the largest wheat producer in sub-Saharan Africa (FAOSTAT, 2014). It is a traditional staple food crop, cultivated by 5 million households on 1.6 million ha of land under rain-fed conditions; and3.9 million tons of wheat production (CSA, 2014). Oromia region is the major wheat producer in Ethiopia with 2.30 million tons of wheat production from the production area of $837,000.48$ ha (CSA, 2014). Similarly, west and southwest Shewa zones are among the major wheat producing areas in Oromia region with 0.32 million tons wheat production from $62,972.01$ ha (CSA, 2014).
Although the productivity of wheat has increased in the last few years in Ethiopia, it is still very low as compared to other wheat producing countries. The national average productivity is estimated to 2.4 tons/ha (CSA, 2014), which is by far below the world's average of 3.3 tons/ha (FAO, 2007). The low productivity is attributed to a number of factors including: Biotic (Diseases, insect pests, and weeds), abiotic (moisture, soil fertility, etc) (Zegeye et al., 2001). Among biotic factors, rust diseases play a significant role in Ethiopia up to $75 \%$ wheat yield loss (Mengistu et al, 1991).

However, stem rust or black rust (caused by Puccinia graminis f. sp. tritici) is a serious wheat disease in Ethiopia. Yield loss due to stem rust in Ethiopia was estimated to reach up to $100 \%$ on susceptible wheat varieties at times of disease 
epidemics (Bechere et al., 2000). According to Leppik (1970) and Singh et al. (2006), the highland of Ethiopia is considered as a hot spot for the development of stem rust races diversity.

Although many improved wheat varieties have been released in Ethiopia, the average use of rust-resistant wheat is only about 4\% (CSA, 2008). One variety, Digalu, accounts for about half of the wheat grown in Ethiopia and other four varieties account for the other 50\% (DRRW, 2010). Digalu occupied over 0.5 million ha (approx. $31 \%$ of production acreage) in Ethiopia and made a major contribution to the record wheat harvest of 3.92 million tons in the 2013/14 season (CSA, 2014). More farmers will need to adopt rust-resistant varieties in order to withstand future rust outbreaks in Ethiopia. Wheat stem rust can be effectively controlled by growing resistant varieties (DRRW, 2010). Studies carried out in Ethiopia showed that most previously identified races such as TTKSK, RRTTR, TTTTR, TTHSR, PTHSR and others were virulent on most varieties grown in the country (Belayneh et al., 2009). Development of resistance varieties, however, requires a knowledge of the wheat reaction with virulent stem rust races, and which resistance genes are effective against dominant races. Hence, this study was planned to evaluate bread wheat varieties to the major virulent stem rust races.

\section{Materials and Methods}

\subsection{Description of the Study Area}

Green house and field evaluation were done in Ambo Plant Protection Research Center (APPRC). It is located at $08^{0} 96^{\prime}$ $885^{\prime \prime} \mathrm{N}$ latitude and $37^{\circ} 85^{\prime} 923^{\prime \prime} \mathrm{E}$ longitude and at an altitude of $2147 \mathrm{~m}$.a.s.l. The annual average temperature and rain fall is $27.54^{\circ} \mathrm{C}$ and $1077.68 \mathrm{~mm}$, respectively.

\subsection{Green House Evaluation of Bread Wheat Varieties Against Dominant Races of Stem Rust at Seedling Stage}

The major spores of prevalent and virulent stem rust races, previously identified from West and Southwest Shewa Zones; by using 20 differential wheat lines, were multiplied on theMcNair line and collected in separate test tubes for inoculation of the wheat varieties. Twelve commonly grown bread wheat varieties, and the susceptible McNair as a check (Table 1) were evaluated against the selected virulent stem rust races (TKTTF and TTKSK). Five seeds of each differential wheat lines and a susceptible check were planted in $3 \mathrm{~cm}$ diameter plastic plots separately. A CRD (Complete Randomized Design) with three replications was used. Seven-day-old seedlings (the first leaf is fully expanded and the second leaf is just emerged to grow), were inoculated with spores of virulent races (approximately $4 \mathrm{mg}$ of spores per $1 \mathrm{ml}$ lightweight mineral oil suspension).

For incubation, inoculated plants were moistened with fine droplets of distilled water by using atomizer after twenty minutes of inoculation and placed in dew chamber for $18 \mathrm{hrs}$ dark period at $18-22^{\circ} \mathrm{C}$ followed by exposureto light at least for $4 \mathrm{hrs}$ to provide favorable condition for stem rust infection.
Seedlings were allowed to dry/remove their dew/ moisture for about 3-4hrs. Following this, the seedlings were transferred from dew chamber to glass compartments in the green house where conditions were regulated at $12 \mathrm{hrs}$ photoperiod, at temperature range of $18-25^{\circ} \mathrm{Cand} \mathrm{RH}$ of $60-70 \%$. Natural day light was supplemented with additional $4 \mathrm{hrs} /$ day that emitted by cool white fluorescent tubes arranged directly above plants in the green house. Data on infection types were recorded 14 days after inoculation according to the host response.

Table 1. List of bread wheat varieties that were used for evaluation against stem rust races.

\begin{tabular}{lll}
\hline Variety Name & Year of Release & Origin \\
\hline Hidasie & 2012 & KARC/EIAR \\
Ogolcho & 2012 & KARC/EIAR \\
ET-13A2 & 1981 & KARC/EIAR \\
Ogena & 2011 & EIAR/ICARDA \\
Shorima & 2011 & KARC/EIAR \\
Huluka & 2011 & EIAR/ICARDA \\
Danda'a & 2010 & KARC/EIAR \\
Kakaba & 2010 & KARC/EIAR \\
Galil & 2010 & Hazera Genetics Ltd (Axum \\
Digalu & 2005 & Green Line Trading Plc) \\
Madda Walabu & 1999 & KARC/EIAR \\
Lakech & N/A & SARC/OARI \\
McNair (Sucpt.ck) & N/A & EIAR \\
Morocco (Sucpt.ck) & N/A & APPRC \\
\hline
\end{tabular}

Source:- APPRC and KARC, 2014

N/A: Not available

\subsection{Field Evaluation of Bread Wheat Varieties Against Stem Rust Race at Adult Plant Growth Stage}

Twelve commonly grown bread wheat varieties and the susceptible check (Morocco) were evaluated against stem rust disease under field condition (Table 1). The susceptible infector (Morocco) rows were planted in the border of experimental plots (Jin et al., 2007) before 7 days of the test varieties and inoculated artificially with TTKSK race. At infection time, samples were taken from each plot and checked in the green house if other races mixed naturally with inoculated race. The experiment was laid out in randomized complete block design (RCBD) with three replications. Each plot consisted of 6 rows with a size of $1.2 \mathrm{~m} \times 2.5 \mathrm{~m}$ and with a spacing of $1 \mathrm{~m}$ between blocks and $0.4 \mathrm{~m}$ between plots. The inter row spacing was $0.2 \mathrm{~m}$. The recommended fertilizer rates $\left(41 / 46 \mathrm{~N} / \mathrm{P}_{2} \mathrm{O}_{5} \mathrm{ha}^{-1}\right)$ and seed rates of $100 \mathrm{~kg} \mathrm{ha}^{-1}$ was used. Weeding and other management practices were followed as recommended for the area.

\subsubsection{Disease severity / Terminal Severity}

It was assessed as proportion of leaf/stem area infected from 10 randomly tagged plants in the central four rows of each plot and the mean of the ten plants was calculated. The stem rust severity scoring began when the infector rows attained about 30 to $50 \%$ susceptible responses based on modified Cobbs' scale where $0 \%=$ immune and $100 \%=$ completely susceptible (Peterson et al., 1948). Disease severity was taken 3 times at ten days interval starting from 
the appearance of the disease. Terminal severity was scored at the maturity stage of the crop.

\subsubsection{Reaction Type}

The reaction type was recorded based on the original scales proposed by Roelfs et al. (1992) for stem rust and other rust diseases in field evaluation.

\subsubsection{Average Coefficient of Infection (ACI)}

It was calculated by multiplying the percentage severity times a constant for host response: where immune $=0.0, \mathrm{R}=$ $0.2, \mathrm{MR}=0.4, \mathrm{MS}=0.8$, and $\mathrm{S}=1.0$. It was calculated by taking in to account the severity of stem rust on the varieties and their field response (Roelfs et al., 1985). The ACI for each variety was computed for three observations recorded at an interval of ten days and ACI was used for calculating AUDPC for each variety.

$$
A C I=\text { Disease sverity percentage } \times \text { Cons } \tan t \text { for response }
$$

\subsubsection{Area Under Disease Progress Curve (AUDPC)}

Itwas calculated using the formula suggested by Wilcoxson et al. (1975).

$$
\text { AUDPC }=\sum_{i=1}^{n-1} 0.5\left(\mathrm{X}_{\mathrm{i}+1}+\mathrm{X}_{\mathrm{i}}\right)\left(\mathrm{t}_{\mathrm{i}+1}-\mathrm{t}_{\mathrm{i}}\right)
$$

Where, $\mathrm{X}_{\mathrm{i}}$ is the cumulative disease severity expressed as a proportion at the $i^{\text {th }}$ observation; $t_{i}$ is the time (days after planting) at the $i^{\text {th }}$ observation and $n$ is total number of observations.

\subsubsection{Disease Progress Rate (' $r$ ')}

The three disease severity observations recorded at 10 days interval were regressed over time and the apparent infection rates (the coefficient of the regression line for each plot) were analyzed by analysis of variance.

\subsection{Data Analysis}

Green house evaluation was analyzed using the descriptive statistics. Analysis of variance (ANOVA) was used for field experiment as randomized block design (RCBD) for one factor, following the procedure described by Gomez and Gomez (1984) using SAS computer software. When the variables were significant, mean separation was done based on LSD at $5 \%$ probability level. The data on AUDPC and infection rate were analyzed after checking for good fitness to ANOVA.

\section{Result and Discussion}

Two virulent races (TKTTF and TTKSK) were inoculated on the test materials at Seedling stage in the green house. Under field condition TTKSK was inoculated on the spreader rows of Morocco. There was no complete resistance (zero infection type) observed in all inoculated wheat varieties both at seedling and adult plant stages (Table 2).

Among the 12 test wheat varieties, three (Danda'a, ET-13A2, and Kakaba) showed susceptible $\left(3^{+}\right)$reaction to both stem rust races at seedling stage in the green house (Table 2). Similarly,
Kakaba and Danda'a varieties exhibited moderately susceptible (MS - medium sized pustules) reaction in the field with terminal severity of $36.7 \%$ and $43.3 \%$, respectively. But, ET-13A2 variety revealed susceptible (S - large pustules without necrosis or chlorosis) reaction with terminal severity of $36.7 \%$. Five wheat varieties such as Huluka, Shorima, Hidasie, Ogolcho and Ogena tested in the greenhouse at seedling stage showed resistance to both races. These wheat varieties tested at seedling stage showed resistance reaction implying the presence of seedling resistance gene towards these two races. Huluka and Ogena showed moderately resistant (MR - small pustules surrounded by necrotic areas) reaction at adult plant stage with terminal severity of $8.3 \%$ and $6.7 \%$, in that order. Whereas, Shorima, Hidasie and Ogolcho varieties had moderately susceptible response with terminal severity of $13.3 \%, 43.3 \%$ and $30 \%$, respectively. Based on greenhouse seedling test, three varieties such as Galil, Madawolabu, and Lakech were resistant to TKTTF race, but susceptible to TTKSK (Ug99) race. On the contrary, Digalu showed resistance to TTKSK race, and susceptible to the new race (TKTTF) at seedling stage. Galil, Madawalabu and Lakech varieties showed moderately susceptible reaction but Digalu revealed susceptible response in field condition. The susceptibility of Digalu at field condition was not due to TTKSK but due to high pressure of TKTTF race that occurred naturally. The stem rust check, McNair was susceptible to both races at seedling stage in the green house. Likewise, the check Morocco exhibited susceptible response at field condition with terminal severity of $73.3 \%$ (Table 2 ).

There was significant $(\mathrm{p}<0.001)$ differences among the commercial bread wheat varieties with regard to AUDPC and infection rate values (Table 2). The highest AUDPC (1225\% day $\left.^{-1}\right)$ and infection rate $\left(0.25\right.$ units day $\left.{ }^{-1}\right)$ were recorded on the susceptible check Morocco. The second highest AUDPC (805.8) and infection rate $(0.125)$ were recorded on Digalu variety, but it was comparable with Madawalabu, Ogolcho and Hidasie varieties in infection rate. The highest terminal severity was recorded on Morocco (73.3\%) followed by Digalu (63.3\%). The least mean AUDPC of 37 was recorded in the Ogena variety, but, it was comparable with Shorima, Huluka and Galil. On the other hand, the lowest infection rate was scored by Lakech (0.033), Ogena (0.023), Shorima (0.03), Huluka (0.02) and Galil (0.03) varieties but statically they were at par with Ogolcho, Kakaba, ET -13A2 and Danda'a.

AUDPC is a good indicator of adult plant resistance under field condition (Wang et al., 2005). It is directly related with the yield loss (Subba Rao et al., 2008) and provides critical information for designing effective disease management practices for genotypes with different types and levels of resistance (Jeger, 2004). Varieties which had low AUDPC and terminal severity values may have good level of adult plant resistance (Wang et al., 2005). In this study, the lowest AUDPC values were recorded in Ogena, Huluka, Galil and Shorima (Table 2). In the same order, the terminal severities were also as low as $6.7 \%, 8.3 \%, 26.7 \%, 13.3 \%$. But, Ogena and Huluka varieties showed better resistance at both seedling and adult plant stages (Table 2). Seedling resistance genes which also work at the adult plant stage usually confer strong resistance 
response (Singh et al., 2008).

Varieties such as Ogena, Shorima, Huluka and Galil can be considered as a slow rusting due to low AUDPC and terminal severity at adult plant growth stage. Slow rusting is a useful measure of resistance because it is the result of all factors that influence disease development such as differences in environment, varieties and population of the pathogen (Wilcoxson, 1981). Moreover, efforts should be made towards accelerated variety replacement with other resistant and high yielding ones before the virulent stem rust put them out of production. This is because varieties that are resistant to stem rust in one year or one location, may be susceptible in another year or location depending upon the virulence of the pathogen. The most popular variety Digalu that covered $55.8 \%$ of the wheat area in west and southwest Shewa zones of Oromia region, was resistant to stem rust previously, but now has become susceptible to TKTTF race. Stem rust resistant gene SrTmp is found in Digalu cultivar as race specific resistance gene (Ravi et al., 2011) and it was incorporated for Ug99 (TTKSK) resistance. Now this resistance gene has been overcome by virulent race known as TKTTF. Similarly, Danda'a and Kakaba were released as a stem rust resistant varieties and their popularity also increased in most areas of the country including west and southwest Shewa zones of Oromia region. $\mathrm{Sr} 2$ is found in both varieties as adult plant stage resistance (Ravi et al., 2011). This study showed that, high infection type $\left(3^{+}\right)$was recorded on the Danda'a and Kakaba varieties at seedling stage, but they have a little potential to resist TTKSK race in adult plant stage.

The susceptibility of Digalu indicates the potential threat of TKTTF, and currently high yielding bread wheat varieties such as Danda'a, Kakaba and Shorima might be out of production if resistance gene will not be developed for this virulent race. However, Digalu showed negative response (low disease infection) to TTKSK race both at green house and field condition. Worku et al. (2013) reported similar findings that, Digalu variety was resistant to TTKSK (Ug99) at field and seedling stages in Debre zeit, 2007/8 main growing season with $20 \%$ terminal severity and low infection type $\left(2^{+}\right)$. They also reported that, Madawalabu and ET-13A2 varieties showed susceptible reaction to TTKSK race at seedling and adult plant stage. The present study also showed that, the two varieties were susceptible to TTKSK race at seedling stage; Madawalabu showed MS reaction whereas, ET-13A2 showed S response under field condition for the same race. In addition, Belayneh, (2009) also reported that Digalu variety was resistant to TTKSK race identified during 2006 and 2007 at seedling stage. Similarly, based on Abebe et al., (2010) thesis report, Digalu was resistant to TTKSK race at seedling stage from southern Tigray isolates. The present study confirms with the above mentioned authors' report as to Digalu variety resistant response against TTKSK race. The resistant response of Digalu variety at both plant growth stages to TTKSK race could be the presence of SrTmp gene. Conversely, the susceptible response of Digalu at both plant growth stages to TKTTF race might be the virulence of TKTTF on SrTmp resistant gene. Danda'a and Kakaba varieties were susceptible to TTKSK and TKTTF races at green house test due to lack of seedling stage resistant genes; and they showed MS response in field condition to TTKSK race and this might be due to the availability of adult stage resistant gene.

Taye et al., (2014) reported that, Shorima showed a better resistance (slow rusting) to stem rust in field condition in Guji zone, southern Oromia during main season of 2011. They also reported that, Kakaba, Danda'a, Digalu, ET-13A2 and Galil varieties were ranked as moderately resistant to stem rust at adult plant growth stage. However, varieties such as Kakaba, Danda'a, Shorima and Galil varieties showed moderately susceptible response whereas, Digalu and ET-13A2 showed susceptible response under field condition in the present study.

Table 2. Reaction of bread wheat varieties to stem rust at seedling stage (in the greenhouse) and adult plant growth stage (under field) conditions at Ambo PPRC, during 2014 main season.

\begin{tabular}{|c|c|c|c|c|c|c|}
\hline \multirow{2}{*}{ Varieties } & \multicolumn{2}{|c|}{ Seedling reaction (IT) to race } & \multicolumn{4}{|l|}{ Field reaction to TTKSK } \\
\hline & TKTTF & TTKSK & Terminal severity $(\%)$ & Host response & AUDPC & Infection rate (Units) \\
\hline Digalu & 3 & 2 & 63.3 & $\mathrm{~S}$ & $805.8 \mathrm{~b}$ & $0.125 b$ \\
\hline Danda'a & $3^{+}$ & $3^{+}$ & 43.3 & MS & $404.7 \mathrm{c}$ & $0.047 \mathrm{cde}$ \\
\hline Galil & $; 1$ & 3 & 26.7 & MS & $245.7 \mathrm{cdef}$ & $0.03 \mathrm{e}$ \\
\hline Huluka & $; 2^{-}$ & $; 1$ & 8.3 & MR & $52.7 \mathrm{ef}$ & $0.02 \mathrm{e}$ \\
\hline ET-13A2 & $3^{+}$ & $3^{+}$ & 36.7 & S & $395.7 \mathrm{c}$ & $0.043 \mathrm{de}$ \\
\hline Kakaba & $3^{+}$ & $3^{+}$ & 36.7 & MS & $378.7 \mathrm{c}$ & $0.053 \mathrm{cde}$ \\
\hline Hidassie & $2^{+}$ & $2^{-}$ & 43.3 & MS & $431.3 \mathrm{c}$ & $0.10 \mathrm{cb}$ \\
\hline Ogolcho & $; 2^{-}$ & $; 2^{+}$ & 30 & MS & 271.3 cde & 0.073 cbde \\
\hline Madawalabu & ;2 & 3 & 33.3 & MS & $287.0 \mathrm{~cd}$ & $0.09 \mathrm{cbd}$ \\
\hline Ogena & $; 2^{-}$ & $; 2^{+}$ & 6.7 & MR & $37.0 \mathrm{f}$ & $0.023 \mathrm{e}$ \\
\hline Lakech & $; 2^{-}$ & 3 & 43.3 & MS & $418.0 \mathrm{c}$ & $0.033 \mathrm{e}$ \\
\hline Morocco/McNair & $3^{+}$ & $3^{+}$ & 73.3 & $\mathrm{~S}$ & $1225.0 \mathrm{a}$ & $0.25 \mathrm{a}$ \\
\hline Mean & & & & & 389.0 & 0.071 \\
\hline $\mathrm{CV}(\%)$ & & & & & 33.8 & 46.083 \\
\hline
\end{tabular}

* Means with the same letter are not significantly different

AUDPC:- Area under disease progress curve; IT:- infection type; LSD:- Least significant difference; CV:- coefficient of variation.

N.B. The S response of Digalu under field condition was due to natural infection of TKTTF; not by TTKSK 


\section{Conclusion}

Evaluation of wheat varieties for their resistances is very important in integrated stem rust management. Most of the tested bread wheat varieties do not have adequate resistance for dominant races (TKTTF and TTKSK) at seedling and adult plant stages. However, Huluka and Ogena varieties showed relatively resistance reaction to dominant races at both plant growth stages, with minimum AUDPC, terminal severity and infection rate under field condition. These varieties can be used as sources of stem rust resistance genes for the study area. Therefore, regular assessment and evaluation of wheat varieties against stem rust races will be mandatory for virulence and/or avirulence information in west and southwest Shewa zones. Moreover, there should be an urgent need for developing new wheat varieties resistant to the dominant stem rust races (TTKSK and TKTTF).

\section{Acknowledgement}

I am deeply grateful and indebted to EIAR for allowing me to pursue postgraduate study at Ambo University. In this regard, I would like to express my deep and heartfelt gratitude to Dr. Asenak Fikre, for his positive support to start my M.Sc. on time. I would like to thank East African Agricultural Productivity Project (EAAPP) for partial financial support to conduct this M.Sc. thesis work. In this regard, I also owe my deepest gratitude to Dr. Alemayehu Asefa and Mr. Endale Hailu for their role to attach me to the project.

\section{Reference}

[1] Abebe T, Woldeab G, Dawit W (2010) Distribution and Physiologic Races of Wheat Stem Rustin Tigray, Ethiopia. J Plant Pathol Microb 3:142. doi:10.4172/2157-7471.1000142.MSc Thesis.

[2] Bechere E, Kebede H and Belay G. 2000. Durum wheat in Ethiopia: An old crop in an ancient land. Institute of Biodiversity Conservation and Research (IBCR), Addis Ababa, Ethiopia.68pp.

[3] Belayneh, A., 2009. Genetic and virulence diversity of Puccinia graminis $f$. sp. tritici population in Ethiopia and stem rust resistance genes in wheat. PhD. Thesis. University of Giessen, Cuviller Verlag Gottingen, Germany. pp 1-20.

[4] Central Statistical Authority (CSA). (2008). Agricultural Sample Survey 1998/99. Report on Area and Production of Major Crops Volume 1. Statistical Bulletin 200. CSA, Addis Ababa, Ethiopia. 111 pp.

[5] CSA. 2014. Agricultural Sample Survey, 2013/2014. Report on Area and production of Majorcrops. CSA May 2014. Available at: www.csa.gov.et.

[6] Durable Rust Resistance in Wheat (DRRW) Phase II (2010). Proposal for Bill and Melinda Gates Foundation. Cornell University Office of International Programs.

[7] FAO. 2007. Crop prospects and food situations: Global cereal production brief. Available athttp://www.fao.org.
[8] FAOSTAT. 2014. FAO Statistical database. Available at: http:// faostat.fao.org/.

[9] Gomez, K. A. and A. A. Gomez. 1984. Statistical procedure for Agricultural Research $2^{\text {nd }}$ ed. John Wiley and Sons. New York.

[10] Jeger, M. J. 2004. Analysis of disease progress as a basis for evaluating disease management practices.

[11] Jin, Y., R. P. Singh, R. W. Ward, R. Wanyera, M. Kinyua, P. Njau. ZA Pretorius 2007.Characterization of seedling infection types and adult plant infection responses ofmonogenic Sr gene lines to race TTKS of Puccinia graminis $f$. sp. tritici. Plant Dis.91:1096-1099.

[12] Leppik EE (1970). Gene centers of plants as sources of disease resistance. Ann. Rev. Phytopathol., 8: 323-344.

[13] Mengistu H, Getaneh W, Yeshi A, Rebka D and Ayele B. 1991. Wheat pathology research inEthiopia. PP: 173-218. In: Wheat research.

[14] Peterson, R. F., Campbell, A. R., and Havnah, A. E. 1948. A diagrammatic scale for estimating rust intensity on leaves and stem of cereals. Canadian Journal Research. 26: 490-500.

[15] Ravi, S., David, P., Hodson, Julio Huerta-Espino, Yue, J., Sridhar, B., Petter, N., Sybil, H. F., Pawank, S., Sukhwinder, S., and Velv, G. 2011. Fungus is a threat to world wheat production. Annu. Rev. Phytopathol. 2011. 49: 465-81

[16] Roelfs, A. P. 1985. Epidemiology in North America. Pp. 403-434 in A. P. Roelfs and W. R. Bushnell, eds. The Cereal Rusts Vol. II; Diseases, Distribution, Epidemiology, and Control. Academic press, Orlando.

[17] Roelfs, A. P., Singh., R. P., and Saari, E. E. 1992. Rust Diseases of Wheat: Concept and Methodsof Disease Management. Mexico, D. F: CIMMYT. pp 81.

[18] Singh, R. P., Hodson, D. P., Jin, Y., Huerta-Espino, J., Kinyua, M. G., R., Njau, P., and Ward, R. W. 2006. Current status, likely migration and strategies to mitigate the threat to wheat production from race Ug99 (TTKS) of stem rust pathogen. Perspectives in Agriculture, Veterinary Science, Nutrition and National Resources 1: 1-13.

[19] Singh RP, Hodson DP, Huerta-Espino J, Jin Y, and Njau P (2008). Will stem rust destroy the world's wheat crop? $A d v$. Agron. 98:271-309.

[20] Subba Rao K. V, J.P Snow and G. T Berggren 2008. Effect of growth stage and Initial inoculum Level on the Leaf Rut Development and Yield loss caused by Puccinia recondita f. $s p$. tritici Article first published online: 1 May 2008.

[21] Taye, T., Chemeda, F., and Getaneh, W. 2014. Evaluation of wheat cultivars for slow rusting resistance in Guji Zone, Southern Oromia. Afr. J. Agric. Res.

[22] Wang ZL, Li LH, He ZH, Duan X, Zhou YL, Chen XM, Lillemo M, Singh RP, Wang H Xia XC,2005. Seedling and adult plant resistance to powdery mildew in Chinese bread wheat cultivars and lines. Plant Diseases 89:457-463.

[23] Wilcoxson RD, 1981. Genetics of slow rusting in cereals. Phytopathology 71: 989-/993.

[24] Wilcoxson, R. D., Skovmand, B. and Atif, A.H.1975. Evaluation of wheat cultivars ability to retard development of stem rust. Annals of Applied Biology 80: 275-2181. 
[25] Worku, D., Ayele, B., and Tameru, A. 2013. Evaluation of Ethiopian Commercial Wheat Cultivars for Resistance to Stem Rust of Wheat race 'UG99'. International Journal of Agronomy and Plant Protection. Vol., 4(1), 15-24, 2013.
[26] Zegeye T, Taye G, Tanner D, Verkuiji H, Agidie A and Mwangi W. 2001. Adoption of improved bread wheat varieties and inorganic fertilizer by small-scale farmers in Yelmana Densaand Farta districts of Northwestern Ethiopia. EARO and CIMMYT. Mexico City, Mexico. 